\title{
Aproximación etnohistórica al trabajo de la pez en las Bárdenas Reales (Navarra) ${ }^{1}$
}

\author{
Ethno Historical Approach to the Work of the Pitch \\ in the Royal Bardenas (Navarre)
}

\author{
Pablo Orduna Portús \\ Etniker Navarra. Red Cultural - Kultursarea
}

\section{RESUMEN}

La producción de pez fue un sector económico importante durante la Modernidad. Hoy en día sólo se conservan algunos restos de sus hornos o pegueras en las Bardenas Reales de Navarra. Atendiendo al examen del trabajo de campo, las fuentes orales y la documentación de archivo y arqueológica, este artículo recoge la información relativa a una artesanía preindustrial ya desaparecida en este territorio. El análisis de los datos intenta reconstruir el posible sistema de producción seguido en ese oficio tradicional y su situación en la economía local.

Palabras clave: Brea, Pegueras, Horno de pez, Bardenas Reales, Navarra.

\section{SUMMARY}

The production of pine tar was an important economic sector for Modern Age. Actually, only some remnants of ovens of pitch, 'pegueras', are preserved in the Royal Bardenas (Navarre). Considering the fieldwork, oral sources and archaeological or historical files, this article collects information about a preindustrial craft yet passed away in this territory. The data analysis attempts to reconstruct the possible manufacturing system followed by this traditional trade and its place in the local economy.

Key words: Pine Tar, Kiln of Pitch, Gum, Royal Bardenas, Navarre.

\footnotetext{
${ }^{1}$ Quisiera agradecer la ayuda prestada por Txaro Mateo en la búsqueda de algunos puntos de partida para la realización de este artículo. Durante los años 2011 y 2013, el grupo Olcairum Estudios Arqueológicos recogió en el transcurso del Proyecto Aguilares interesantes referencias etnográficas en este Parque Natural. El mencionado estudio se inició a partir de la firma entre el Ministerio de Medio Ambiente y Medio Rural y Marino y la Comunidad de Bardenas, de un convenio de colaboración para el fomento de actuaciones de desarrollo sostenible en la Reserva de la Biosfera de Bardenas Reales de Navarra. En tal ámbito de investigación, bajo la dirección de Txaro Mateo, se consolidó un estudio que se publicará bajo el título: Usos tradicionales en el territorio de Bardenas Reales. Dentro del mismo habrá apartados dedicados a la elaboración de pez, la caza, la producción de carbón, recogida de leña o conocimiento de las plantas. Mis agradecimientos son también para Pedro Orduna, informador de campo, y los técnicos de la Sección de Arqueología del Gobierno de Navarra, Jesús Sesma y Jesús García Gazólaz, por los datos ofrecidos.
} 
En los tochos, tollos o bordes de los barrancos bardeneros aún se encuentran restos físicos de un oficio perdido. Se trata de una labor olvidada tanto en el paisaje como en la memoria de aquellos que se han azacanado en sacar provecho a esa tierra aparentemente baldía. Colgados de los pequeños precipicios se aprecian todavía hoy escorias, tizones y endebles estructuras arruinadas. Son los antiguos hornos o pegueras que, tiempo atrás, explotaron los pinos resineros (Pino Carrasco o Alepo - Pinus Halepensis-), de la comarca en busca del pegadizo pero valioso líquido llamado alquitrán, brea o pez.

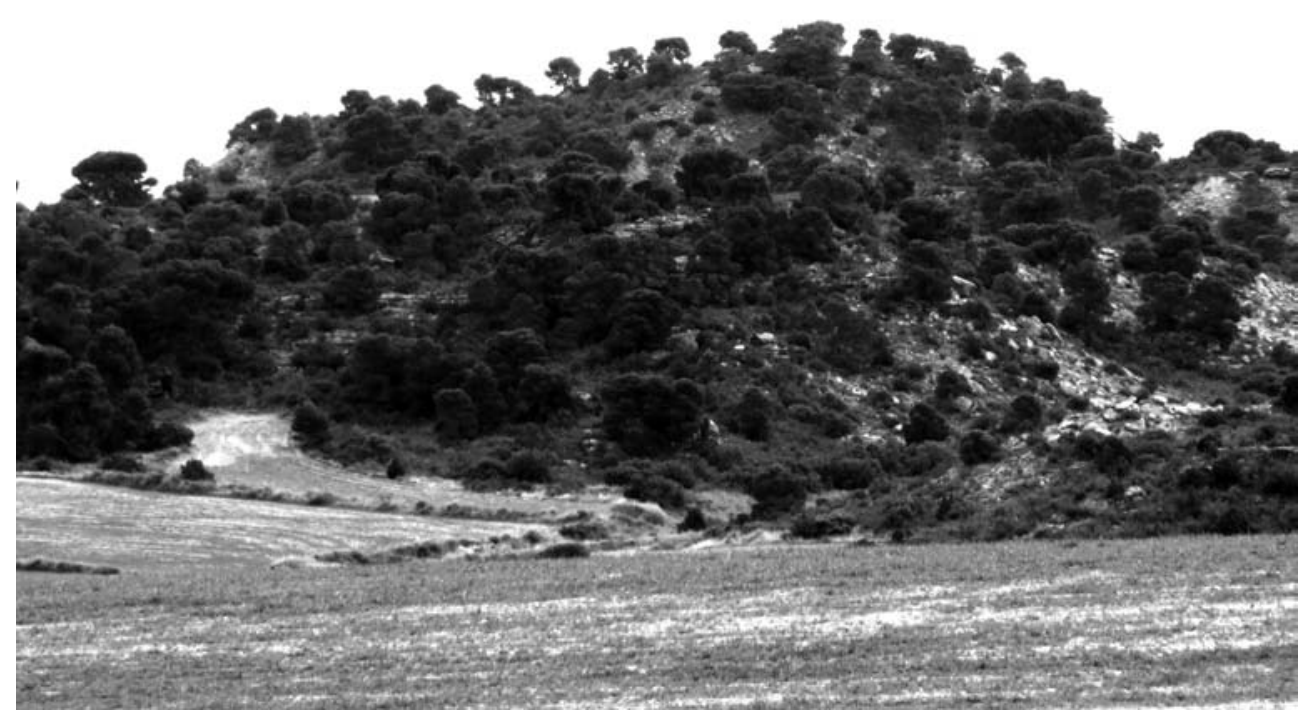

FOTOGRAFía 1.- Pinos carrascos en las Bardenas, 2014.

En este artículo nos hemos acercado a dicho oficio desde tres fuentes de información diferentes. En primer lugar, nos centramos en los datos aportados por un pastor trashumante (Pedro Antonio Orduna) que mantiene en invierno su ganado en las Bardenas. A continuación, analizamos los antecedentes de archivo obtenidos y que abarcan diferentes años de las Edad Moderna. En último lugar se tuvieron en cuenta los documentos analizados en el Inventario Arqueológico de Navarra y las reseñas anotadas en la observación de algunos restos durante el trabajo de campo. Con las aportaciones de fuentes tan diversas pretendemos ofrecer una visión desde tres puntos de vista diferentes: el etnográfico, el histórico y el arqueológico. 


\section{EL OFICIO DE LOS EMPECINADOS}

Por empecinados o pegueros se tenía a aquellos hombres que usando la resina natural de los pinos fabricaban en sus hornos la pez (DRAE 2001). En la Ribera navarra se les denominaba pegueros o pegunteros y su oficio está datado ya en el siglo XV (Orduna et al. 2006: 191)². La sustancia obtenida cobró gran importancia con el tiempo 3 . Debemos recordar que era utilizada luego tanto en manufacturas agropecuarias, como en boterías, marcado de reses, o calafateado de embarcaciones u otras superficies, orgánicas o no, que era necesario impermeabilizar. Por lo tanto su presencia estaba en el día a día de muchos talleres, trabajos y hogares. Por ejemplo, para coser sus piezas, los guarnicioneros utilizan leznas e hilo encerado. Dicho tratamiento a

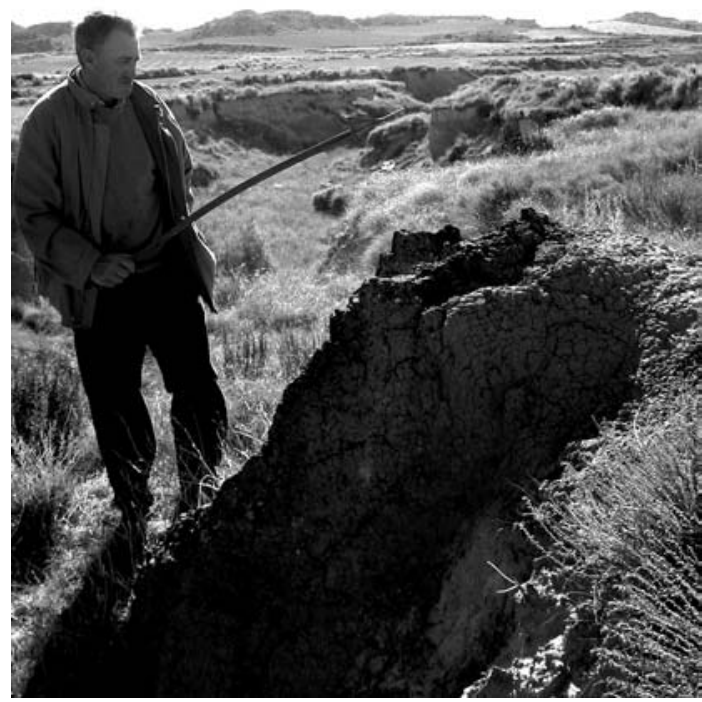

FOTOGRAFÍA 2.-Pedro Orduna junto a un horno de pez, 2007. la hebra, que es de cáñamo con tres y cuatro cabos, lo logran mezclado cera virgen con pez. Tal preparación aporta la capacidad de lograr más fuerza en el momento de hacer el cuerpo del objeto (Orduna et al. 2006: 96).

El proceso de reducción y obtención de esta brea era metódico y seguía un protocolo preciso para evitar posibles accidentes o incendios en los hornos. Este sistema

\footnotetext{
${ }^{2}$ Jesús Sesma y $M^{\underline{a}}$ Luisa García señalan que cerca de yacimientos arqueológicos bardeneros vinculados al Bronce Medio ('Pisquerra I') y al Bronce Medio Evolucionado ('Portillo Lobo' y 'Cuesta de Morón') se han observado estructuras que ellos vinculan a la obtención de pez. Ambos autores fundamentan su hipótesis en la similitud de tales armazones fabriles con ciertos paralelos etnográficos actuales. A su vez, como bien señalan los autores, al no quedar artefactos productivos junto a las pegueras ni materiales donde se han hallado es imposible datar con certeza su construcción en dicho periodo prehistórico (Sesma y García 1994: 145 y 148). Por otro lado, en realidad tal ubicación puede responder a que las buenas condiciones geográficas que buscaron los fundadores de tales poblados fueron igualmente apreciadas por productores de pez de cronologías posteriores. A lo largo de este trabajo haremos referencias a documentación de archivo relativa a estos productores de brea y que está fechada entre los siglos XVI y XVIII. Al siglo XVI parecen remontarse también unas pequerías en Tenerife (Hernández 2007). En cuanto al término peguntero se puede mencionar que éste aparece en el documento: Archivo Real y General de Navarra (ARGN), Tribunales Reales (TT.RR.), 72227.

${ }^{3}$ Tal era la importancia de este producto que en plena Edad Moderna entre los bienes que de forma legal podían portar los canarios hacia América se encontraba la brea (Santana 2007: 83-84). De hecho, durante todo el Seiscientos iba a ser La Habana el principal punto de venta de la pez de La Palma (Lobo, Santana y Toledo 1998: 87 cit. por Santana 2007: 84).
} 
se mantiene vivo en el recuerdo de contornos como el de la Tierra de Pinares en Castilla y León, con alguna que otra variación local (Martínez 2010: 197-206).

Las pegueras o pezgueros se construían en forma aovada y cubiertos con falsas cúpulas. Lo habitual era usar ladrillo refractario para levantarlas. En el caso que nos ocupa no es así y eran levantados con adobe o barro cocido elaborado con la propia tierra del lugar. Tal material era endurecido con fuego prendido en su interior. Además, en algunos casos, se estructuraba sobre un zócalo pétreo. Un ejemplo de ello se halla en el paraje cercano a las Bardenas conocido como Vedado de Eguaras. En tal espacio se localizó un horno peguero sustentado en un suelo de piedra junto a un yacimiento arqueológico altoimperial romano (Sesma y García 1994: 182).

No sabemos si la ubicación elegida respondía a un patrón concreto en las Bardenas o a exigencias de la orografía. En la actualidad gran parte de los que han sido descubiertos se hallan ubicados en los cortados de los barrancos. Hay que mencionar que esta tierra está compuesta por materiales tan endebles como la arenisca, el yeso y la arcilla, que han sido erosionados por el clima y la fuerza hídrica. En este terreno desértico, la cercanía a estos ocasionales cauces de tormenta podría ser por lo tanto más que premeditada. Hay que recordar que se elevaban con adobe y para la obtención de éste hace falta agua. En cualquier caso, en la actualidad todos ellos han acabado colmatados por arena y piedras de manera total o parcial.

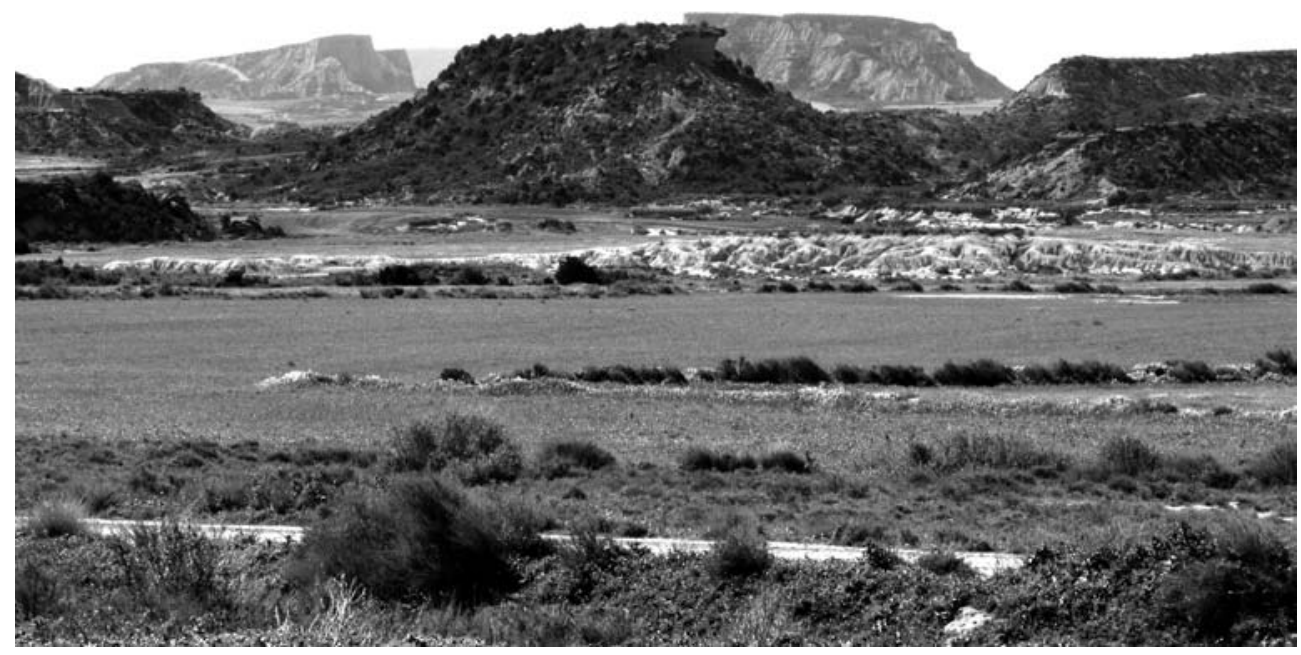

FOTOGRAFÍA 3.-Paisaje bardenero semidesértico, 2012.

Es posible que se buscara esa localización con objeto de poder semienterrar de forma más fácil la parte inferior del artificio y lograr un mayor aislamiento térmico. En otros lugares esto se realizaba mediante montículos artificiales. En las Bardenas, 
parece ser que la orografía y climatología facilitaron la tarea con sus tollos naturales (Soler 2009). Un ejemplo de ello lo encontramos en la propia toponimia menor entre la que se halla el término conocido como el Barranco de la Pez o Barranco del Horno de la Pez donde han aparecido restos de estas estructuras de transformación artesanal. Por otra parte, también se encuentra el término El Hornero, si bien no se

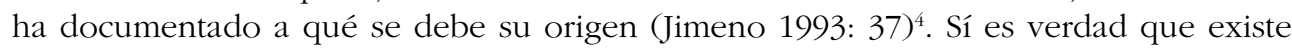
un topónimo menor señalado como cabaña de José el Hornero5. Así mismo, en 1743, en las Bardenas se registraba el término 'Orno de la Quemada' que puede hacer referencia a una de estas estructuras ya que la brea recocida ya no se tiene por cruda sino por quemada 6 .

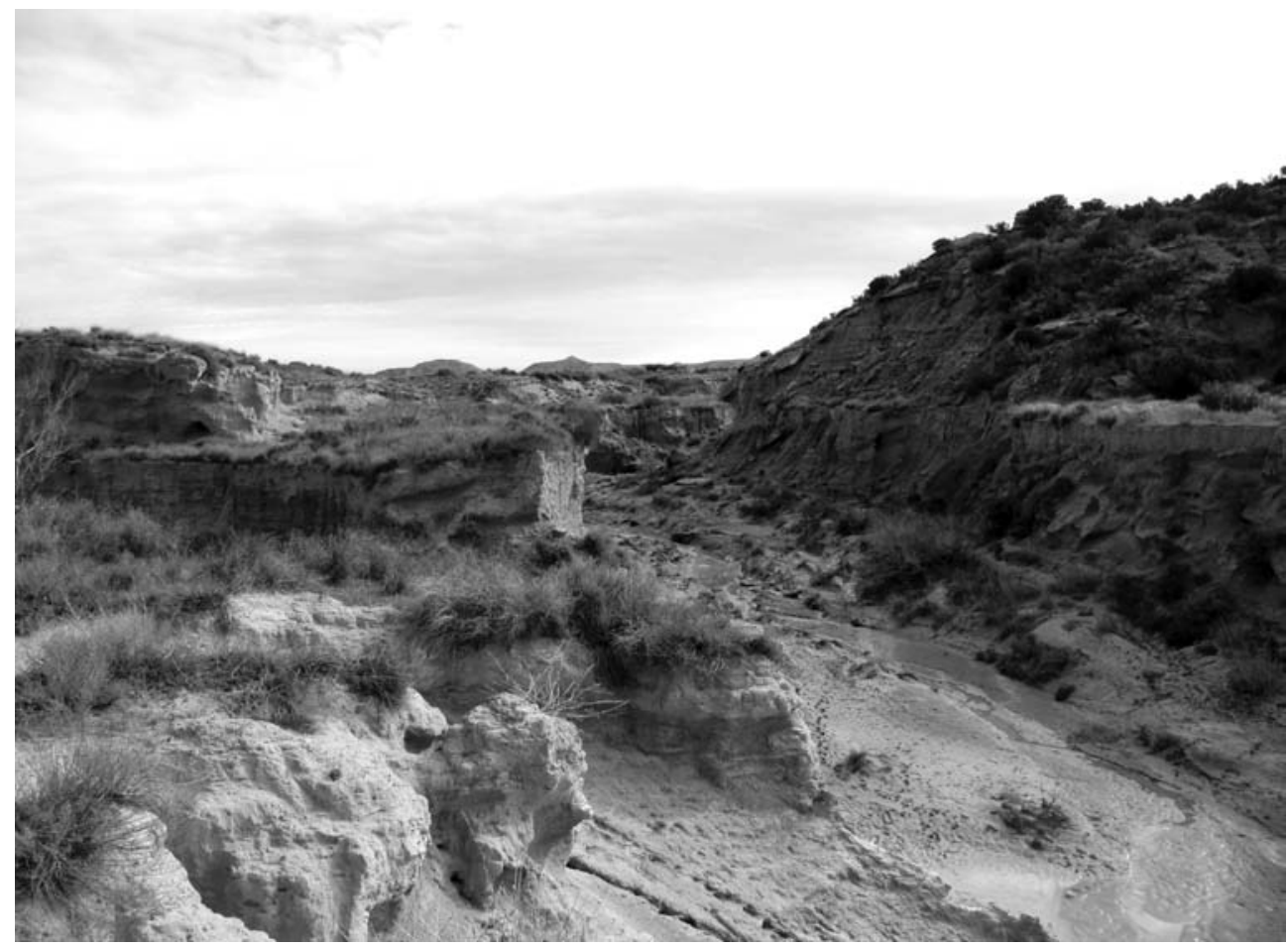

Fotografía 4.-Barranco con desniveles donde se ubican pegueras, 2014.

${ }^{4}$ En 1743 tal lugar era conocido como Cabezo de Ornaz, El Ornaz o Punta de Ornaz (ARGN, Papeles Sueltos (PS), Leg. 77, no 2. Cit por Jimeno, 1993: 77). En el Diccionario de Autoridades de la Real Academia de la Lengua Española no aparece ninguna entrada ni para la voz ornaz ni para hornaz. Tampoco se encuentra dicho término en el de la Real Academia de la Lengua Vasca Euskaltzaindia como palabra de origen vasco. La palabra para referirse a pez en euskara es pike, bike o ui según variedades dialectales, y para denominar al alquitrán obtenido de madera se usa el término egur-mundrun.

5 Sistema de Información Territorial de Navarra (SITNA), Cartografía topográfica, Toponimia UTM X30238 - Y4683528. Captura on line 22 de febrero de 2014.

${ }^{6}$ ARGN, PS, Leg. 77, no 2 (cit. por Jimeno 1993: 119). 
Teniendo en cuenta el periodo de resinación de las coníferas, que se produce entre primavera y otoño, podemos ubicar el momento álgido del trabajo peguero en el ciclo anual durante la invernada ${ }^{7}$. Como se verá más adelante, hay constancia de que en el siglo XVI un peguntero navarro tenía estipulado el tiempo de la brea entre el día de San Martín (11 de noviembre) y mayo ${ }^{8}$. Por otro lado, la materia prima recogida del árbol consistía en tocones, sarros (residuos de resina adheridos a sus hojas o corteza), raíces secas, resina, corteza y la madera de pino?. En algunos lugares como Covaleda (Soria) existían hasta diez tipos de teas según su calidad a la hora de facilitar la producción del alquitrán ${ }^{10}$. Así mismo, atendiendo al tipo de carga que fuera introducida se obtenía una pez más o menos fina y de tonalidad y oscuridad diferente.

Atendiendo a los testimonios de otras regiones, sabemos que una vez aparejadas estas construcciones el proceso comenzaba con la alimentación del horno ${ }^{11}$. La madera picada y la resina pegajosa se cubrían con ramas y barro para evitar que aspirara humo o llama (Soler 2009). Se depositaba sobre un tejido de ramas y hojas verdes que impedía que tocara el suelo del fogón y a la par actuaba de filtro. Sobre él la carga era colocada con intervalos de material verde que permitía ahuecarla en su combustión. Hecho esto, la cavidad utilizada para alimentarse se sellaba habiendo prendido fuego a su combustible. Para dejar salir el aire y respirar, al ingenio crematorio se le practicaba en su parte superior un orificio.

Tal sistema de combustión estaría ardiendo sin parar y sin dejar de ser vigilado, para evitar desgracias, durante dos o tres días. Poco a poco la miera cristalizada se iba derritiendo y deslizándose hacia la parte inferior por canaletas. La pez ya elaborada iba saliendo hacia la parte exterior del horno llegando a una hoya u hoyada semisubterránea que en el caso bardenero aparentan ser una réplica del anterior a inferior tamaño.

Recién acabada la quema, si en la fiera se recogía la pez cruda ésta podía ser envasada para su transporte en el momento (Sanz 1992: 142-14 y Soler 2009). En cualquier caso, el líquido amarillento era aderezado para quitarle el olor a humo cociéndola luego con otros productos vegetales.

En las boterías navarras este proceso fue llevado a cabo hasta el siglo XXI. Cuando la bota de piel (de vino) estaba ya seca y refinada su textura se marcaba serigrafiando

\footnotetext{
${ }^{7}$ Sobre la industria resinera tradicional y moderna ver: Hernández Muñoz (2006).

${ }^{8}$ ARGN, CO_PS, 1ํㅗㅡ S, Leg. 12, nº 56. Año 1593.

9 Para tener una referencia del volumen de producción, en la Tierra de Pinares de Segovia por cada $1.500 \mathrm{~kg}$. de sarros se obtenían unos $500 \mathrm{~kg}$. de brea. A su vez, cada mata de monte pinar destinado a este oficio y repartido entre los vecinos equivalía a entre 500 y 200 árboles así que cada resinero durante cinco años trabajaba entre unos 4.000 y 5.000 pinos (Martínez 2010: 201 y 204). En Tenerife, a mitad del siglo XVII, unos $1.600 \mathrm{~kg}$ de pino canario (Pinus Canariensis) producían de 200 a $240 \mathrm{~kg}$. de pez (Viña y González 2008: 126). En un proceso del último tercio del siglo XVI un peguero navarro deja claro la cantidad y calidad de pino y resina que son necesarios para poder producir pequeñas cantidades de pez.

${ }^{10} \mathrm{http}: / /$ historiadecovaleda.wordpress.com/2013/04/09/los-hornos-de-pez/ Recuperado el 19 del 2 de 2014.

${ }^{11}$ Hay que señalar que en la actualidad ningún vecino de los que Pedro Orduna ha consultado en los pueblos limítrofes recuerda ni la vigencia de este oficio hasta fechas recientes ni siquiera su existencia antaño. Y es reseñable que algunos de ellos tienen restos de hornos en los márgenes de sus campos de labranza.
} 
FOTOGRAFÍA 5.-Vista superior de la caldera del horno del Cebedeo,

2013.

FOTOGRAFÍA 6.-Vista inferior caldera del horno del Cebedeo, 2013.
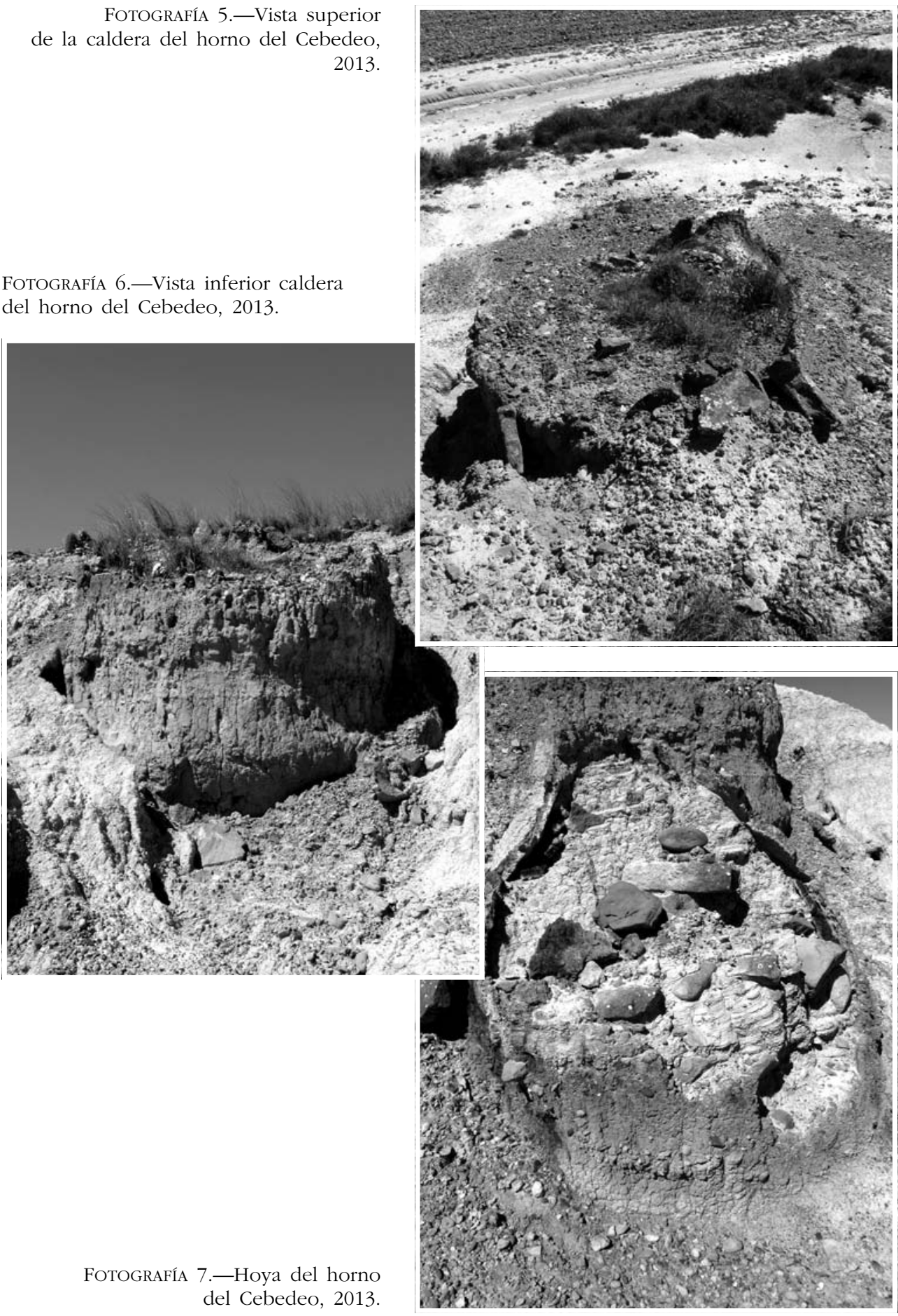

Revista de Dialectologia y Tradiciones Populares, vol. LXIX, n. ${ }^{\circ}$ 2, pp. 413-433, julio-diciembre 2014, ISSN: 0034-7981, eISSN: 1988-8457, doi: 10.3989/rdtp.2014.02.008 


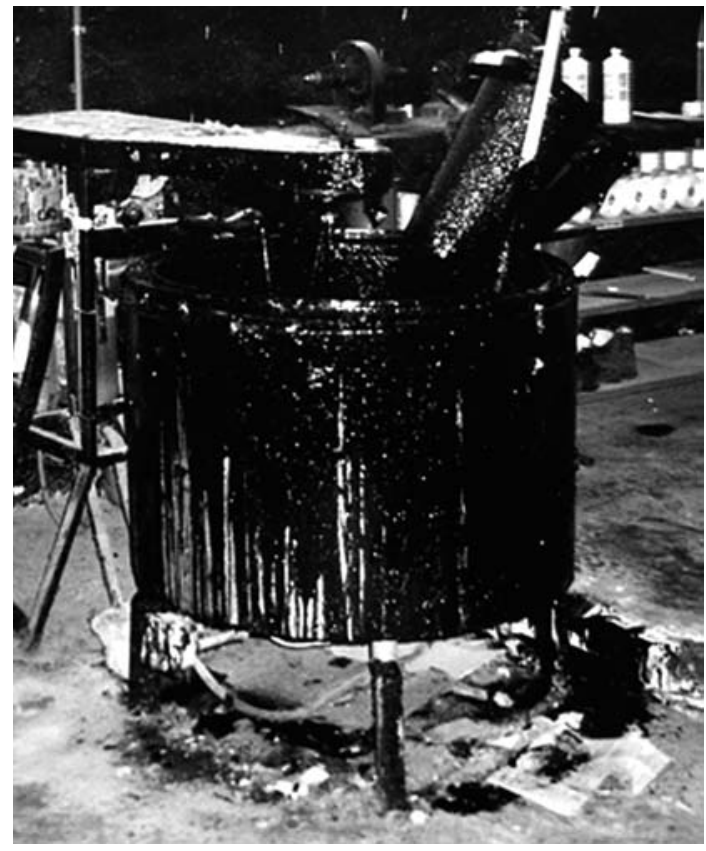

FOTOGRAFÍA 8.-Máquina de embrear en una botería navarra, 2005. la marca del productor. A continuación llegaba el momento de impermeabilizarla recubriendo su interior de pez. Tal acción era denominada 'empezgado'. A comienzos del siglo XXI, para este último proceso la pez se compra a un artesano 'peguero' aragonés que la elabora mediante una fórmula especial que la hace más fina. Tal dinámica consiste en fabricar brea horneando juntas resinas de abeto y pino aderezadas con naranjas, cebollas, limones, ajos y lechugas. Tal efecto además de quitarle el tufo a humareda ofrece en las botas un sabor afrutado al vino ${ }^{12}$. Antes tenían que fabricarla ellos. En la botería San Fermín, creada en 1873 por la familia Echarri y sita en Ansoáin, aseguraban que ante la falta de tales artesanos pegueros tuvieron que producirse ellos la pez durante varios años (Orduna et al. 2006: 99-100).

Si se prefería almacenarla sólida se tenía que quemar de nuevo a unos $300^{\circ} \mathrm{C}$ en el pozo u hoya con todos los conductos de ventilación que pudiera haber cerrados (Martínez 2010: 204). El proceso se prolongaba más de una hora y había que remover de vez en cuando el líquido viscoso con una vara. Recogido un poco del producto de este crisol era evaluado para confirmar que su calidad era la óptima. Una vez seco se observaba si con la fuerza de aplastarlo se hacía polvo o no. Si el resultado era positivo se le daba el visto bueno.

Este era un momento peligroso en tal quehacer ya que la boca podía escupir brea ardiendo o incluso prenderse hacia afuera por una mala combustión o una entrada excesiva de oxígeno. Un ejemplo de varios hornos de pez ardiendo se vivió en Covaleda (Soria) en $1960^{13}$.

Al concluir este proceso, el fuego era ahogado y se dejaba solidificar el resultante, llamado 'pez griega' o 'colofonia negra', en moldes (Martínez 2010: 201). A tal subproducto destilado se le daba el destino de obtener trementina o fabricar colas, barnices, etc. En el caso nuestro de las Bardenas sólo sabemos por documentación histórica que lo obtenido se empleó para realizar betún (pez solidificada) y resina ${ }^{14}$.

${ }^{12}$ Tal brea sólo puede ser utilizada en las botas y pellejos destinados al vino ya que el resto de bebidas gaseosas o con mayor graduación alcohólica pueden disolver esta sustancia. Por ello, en la actualidad se fabrican botas con látex para poder contener esos líquidos y espiritosos (Orduna et al. 2006: 100).

${ }^{13}$ http://historiadecovaleda.wordpress.com/2013/04/09/los-hornos-de-pez/ Recuperado el 19 del 2 de 2014.

14 ARGN, CO-Doc., caj. 109, nº 10, 25. Año 1424. 


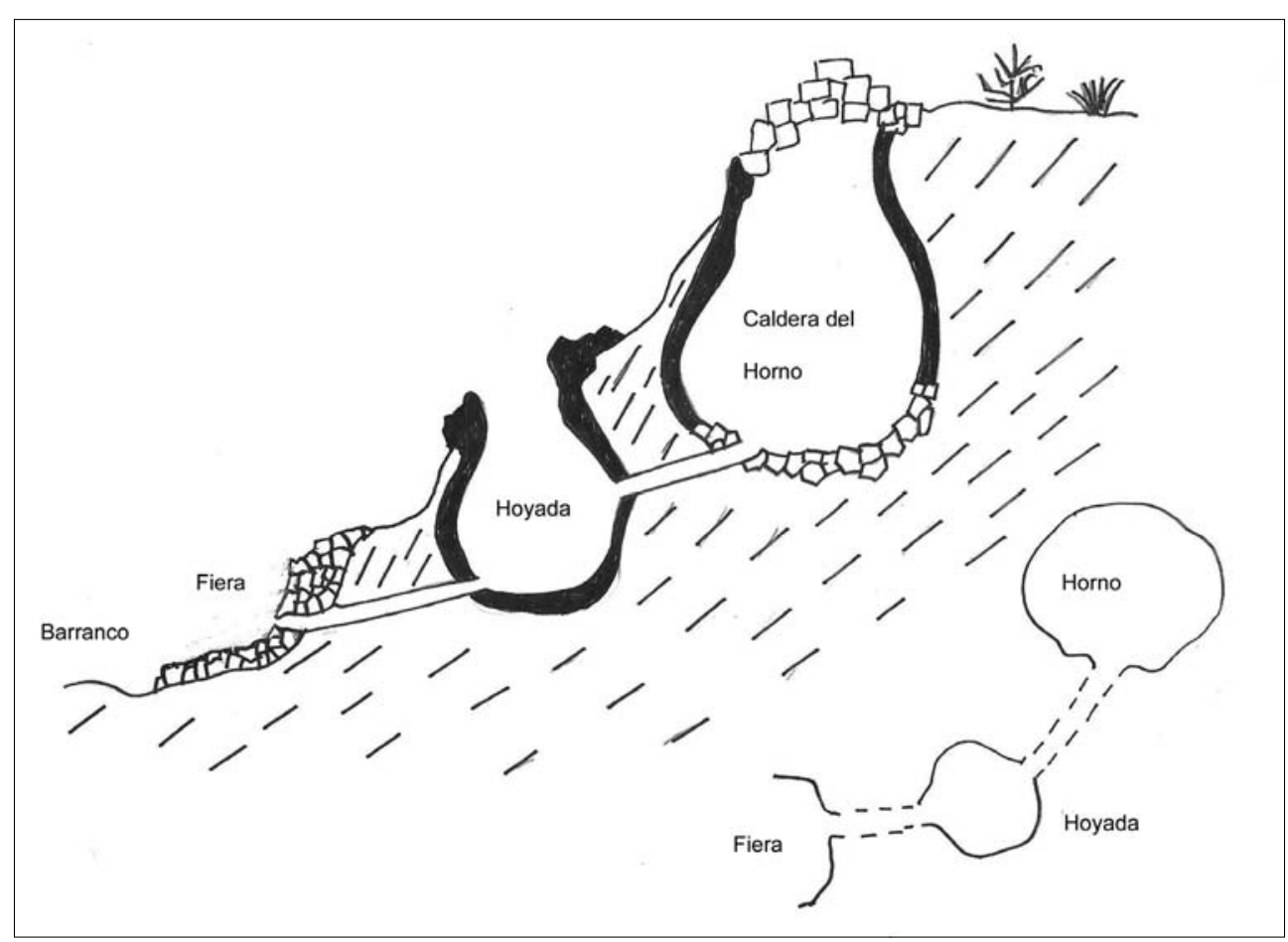

GRÁFICO 1.-Corte de sección vertical y esquema de planta de una peguera bardenera completa. (Fuente: Elaboración propia)

\section{UNA HISTORIA ALQUITRANADA}

Como se ha mencionado, en la actualidad ningún informante local recuerda haber visto vivo el oficio de peguero en el Mediodía navarro, y mucho menos dentro de las Bardenas Reales. De esta manera, viendo que no había resultados en la búsqueda de información por las fuentes orales, se acudió al Archivo Real y General de Navarra. En tal centro archivístico la primera referencia al trabajo de la brea se localizó en el siglo XV y la última mención en el XVII.

En 1424, el tendero de la villa de Tafalla Juan García de Pueyo reconocía haber recibido 11 libras y 1 sueldo de Juan Pérez de Tafalla ${ }^{15}$. Éste era el recibidor de la Merindad de Olite, donde se halla sita Tafalla, pero además, el clérigo de las obras reales de la entonces aún villa tafallesa. Tal prohombre había tenido que pagar el 28 de diciembre de ese año a Juan García por la compra de betún, resina, sebo y pez para la realización de algunas faenas de construcción ${ }^{16}$. En la misma sección de papeles Sueltos del mencionado fondo documental, encontramos la adjudicación a fa-

\footnotetext{
${ }^{15}$ La libra navarra como moneda equivalía a 60 maravedís navarros o lo que es lo mismo, 3 reales y 6 maravedís de vellón. El sueldo navarro equivalía a medio real (Iribarren 1997: 300 y 477).

16 ARGN, CO-Doc., caj. 109, no 10, 25. Año 1424.
} 
vor de Domingo de Yzel del derecho para hacer pez en las Bardenas Reales. El 9 de febrero de 1593 el señalado Procurador Patrimonial emitía tal otorgamiento en Pamplona con la advertencia de que "tampoco pueda hazer la dicha pez si no es entre hornos, y no pueda trabajar a la vez sino es en uno y acabado aquel en otro y no en más". A su vez le señalaba que sólo podía bajar a producir la brea "en el día de San Martín hasta por todo el mes de mayo" por el tiempo de un trienio.

De los tres documentos se extraen ideas muy claras acerca de este oficio en $\mathrm{Na}$ varra. En primer lugar que se trataba de una labor rentable y por lo tanto controlada por las altas administraciones (lo adjudica el Procurador Patrimonial del Viejo Reino) ${ }^{17}$. Para que esa rentabilidad diera sus frutos el proceso se alargaba varios años (tres en este caso) y además tenía un destino asegurado con una multiplicidad de subproductos (vemos el ejemplo de las obras acometidas en Tafalla). Así mismo, se buscaba el control del volumen y seguridad de su producción mediante el reglaje del uso de los hornos en tiempo dispares y no de forma conjunta por el mismo peguero.

Ahora bien, un negocio en apariencia tan rentable no iba a dejar sin trabajo a los Tribunales Reales de Pamplona. Así, entre el siglo XVI y el siglo XVII, existen catalogados seis procesos judiciales. Las autoridades de la Corona Navarra no dudan en proteger el producto.

El primero de ellos acontecía 1538 cuando el Fiscal acusaba al bonetero tudelano Pedro de Soria por haber construido en las Bardenas Reales unos hornos y realizar caza en ellas en tiempo de veda sin permiso. Durante el tiempo que estuvo trabajando en el territorio llegó a cortar 6.000 pinos y parece ser que mantuvo una industria doble de elaboración de pez y tejas ${ }^{18}$. De nuevo en el año 1573 el Patrimonial tomaba cartas en el asunto. Esta vez ejercía el cargo Martín de Viguria y pleiteaba contra la ciudad ribera de Tudela. En las salas de los tribunales se oponía a que ésta tuviera el derecho de arrendar los derechos de caz y de elaboración o recolección de productos como el yeso, jabón, ceniza, carbón... y pez en las Bardenas. Aunque en un primer momento la sentencia no le fue favorable, después, por vía de reconvención, se lograba la inhibición de dichos arriendos ${ }^{19}$.

En este proceso judicial se especifica que:

para hacer pez se requiere para poca pez cortar muchos pinos en gran número. La pez no se puede hacer de leña seca ni de raíces secas pues no tienen humor donde pueda sacar la pez, que la pez y la resina sale del humor de los árboles que se cortan verdes y de la undura que tiene sale la pez y para hacer poca pez hay necesidad de muchos ár-

\footnotetext{
${ }^{17}$ La figura del Patrimonial estaba presente en todas aquellas cuestiones que atañeran a los recursos naturales de un territorio tan pequeño y sujeto a su buen aprovechamiento como Navarra. Es decir, este asunto de la pez atañía y afectaba al patrimonio real y a su integridad. Ya en el siglo XVIII, 1784-1786, dicho Patrimonial se querellaba en Pamplona contra los maestros canteros Pero de Goñi y Gregorio Saldías, vecinos de Caparroso y Villafranca respectivamente. Ambos riberos habían construido un horno de cal en las Bardenas Reales haciendo cargas de romeros y sabinas. Es interesante señalar que en tal proceso se menciona una sentencia dictada en Pamplona el 7 de noviembre de 1498 por los reyes privativos de Navarra. En ella se marcaban los límites para el aprovechamiento de determinados recursos en las Bardenas Reales. ARGN, CO_PS, $1^{\underline{a}} \mathrm{~S}$, Leg. $79, \mathrm{n}^{\mathrm{o}}$ 10. Sobre esta figura de la administración hacendística navarra y su papel en la defensa de los intereses reales ver: Ostolaza (1993).

18 ARGN, TT.RR., 63890.

19 ARGN, TT.RR., 097940.
} 
boles cortados y raíces cortas verdes porque de las ramas, raíces y leña seca no sirve de cosa alguna pues están sin humor. No se puede sacar sino carbón ${ }^{20}$.

Los juicios contra la urbe tudelana no iban a dejar de sucederse. Así, en 1605, otra vez se le enfrentaba y acusaba a sus guardas por poner impedimentos a los arrendatarios bardeneros de tal derecho. Según el demandante se les había llegado a realizar "prendamientos" de todo tipo de materiales con tal fin. Es más, se le derribaron los hornos construidos a pesar de que los 'pegunteros' parecían tener derecho de explotación por tres años. Se habían utilizado pinos de las "endreceras" cercanas a sus ingenios de quema $^{21}$. Ese mismo año se le unía el fiscal para llevar juntos a juicio a los mismos guardas que seguían poniendo dificultades en el disfrute de la caza, la leña y la producción de yeso, jabón, ceniza, carbón, fusta y pez requisando de nuevo utensilios en las Bardenas. La concesión se había resuelto por el sistema de subasta entre los pretendientes ${ }^{22}$. Cuatro años después, el oscense vecino de Villanúa, Francisco Izuel, asumía el papel de demandante frente a su convecino Juan de Asla. Éste residía en Caparroso y era el arrendador del derecho a hacer pez en las Bardenas. Se trataba de una desavenencia derivada del proceso de subasta de tal derecho de explotación mediante el sistema de candela. Por tal método las pujas eran alzadas hasta que la vela moría ${ }^{23}$.

Ya en 1630, el pamplonés Beltrán de Eugui, como apoderado del cascantino Juan de Eugui y Subiza, demandaba a Juan de Erraza. Este era botero en Pamplona y le debía 96 reales de una carga de 25 docenas de pez producida en la Ribera navarra ${ }^{24}$.

Si nos acercamos a la presencia de la pez y sus derivados a nivel municipal se puede mencionar que en 1648 era anotado en el Libro de Cuentas del Concejo de Ororbia la reseña de "haverse gastado el día que se adrezó la fuente entre los jurados y mayorales y la cal y otras cossas" medio ducado. Y medio siglo después, en 1706, el pago de 18 reales «en betún para la fuente que se an gastado doce libras de betún a real y medio" 25 .

Finalmente, podemos apuntar que en los balances hechos en la Tablas de Navarra de 1816 destacaba que la pez estaba entre los géneros introducidos en el Reino desde Castilla y Aragón (Yanguas y Miranda 1840: tomo I, 240). Se observa por lo tanto una carestía del producto y una continuidad de su producción fuera de las mugas del Viejo Reino navarro, a la par que hace suponer su posible desaparición del suelo navarro.

\footnotetext{
${ }^{20}$ ARGN, TT.RR., 097940, fol. 9.

${ }^{21}$ ARGN, TT.RR., 72227. En navarra por 'endrecera' se entiende un sinónimo de paraje, término o incluso barrio (Iribarren 1997: 205).

22 ARGN, TT.RR., 72228

23 ARGN, TT.RR., 57538.

${ }^{24}$ ARGN, TT.RR., 150856. La docena era una medida de peso que en Navarra equivalía a 4,464 $\mathrm{kg}$. Se trataba de la tercera parte de una arroba y equivalía a 12 libras. Si se trataba de medir aceite su equivalencia era de 4,92 1. La libra prima en el Viejo Reino equivalía a 12 onzas de peso en casi todas las vituallas exceptuando el oro y la plata -8 onzas - , la carnicera - 36 onzas - y la pescadera -18 onzas- (Novíssima Recopilación de las leyes del Reino de Navarra, lib 1ํo, tit. 28, ley $1^{\text {a }}$ —vigentes entre 1512 y 1716_ cit. por Iribarren, 1997: 195 y 300). En el proceso se especifica que el valor de cada docena será de 4 reales.

${ }^{25}$ Archivo Diocesano Pamplona (ADP), Parroquias. Ororbia. 933/4. Libro de Cuentas del Concejo. Estos datos han sido aportados por el historiador Pablo Guijarro Salvador que desarrolla un proyecto de investigación monográfico sobre la localidad navarra de Ororbia, perteneciente a la Cendea de Olza.
} 


\section{LAS HUELLAS DE LA PEZ EN LAS BARDENAS}

Hasta hoy, en las 42.000 ha. de las Bardenas Reales han sido localizados diez hornos de pez a los que hay que sumar otro más en el cercano paraje del Vedado de Eguaras (Valtierra) y uno más en otra localidad congozante llamada Pitillas. Así mismo, han tenido que ser diferenciados de nueve caleras ubicadas en parajes cercanos: Barranco del Carrascal, El Junquillo, Molinaz, Sarda del Trillo (5) y Sierra. Uno de los que finalmente se han tenido en este trabajo por peguera en un principio causó dudas. Se trata del horno hallado junto al yacimiento La Futura II en el término del Barranco de Tudela ${ }^{26}$.

Por otro lado, Pedro Antonio Orduna afirma haber visto a lo largo de sus años como ganadero en las Bardenas restos de otros hornos sobre terreno no accidentado que podrían corresponder a hornos de cal. A la par, señala que hay otro que se corresponde a la tipología propia de una peguera en los contornos del Polígono Militar de Tiro, sito en el Parque Natural.

En cualquier caso, se cuenta con 13 hornos pegueros localizados en esta comarca, de los cuales 12 se hallan dentro de las Bardenas Reales y otro, como ya hemos dicho, en el colindante Vedado de Eguaras. Todos ellos muestran unas características estructurales similares.

Se trata de hornos que cuentan con una cámara superior de cremación de un eje máximo de anchura de entre metro y medio y dos metros. Dichas secciones aparecen

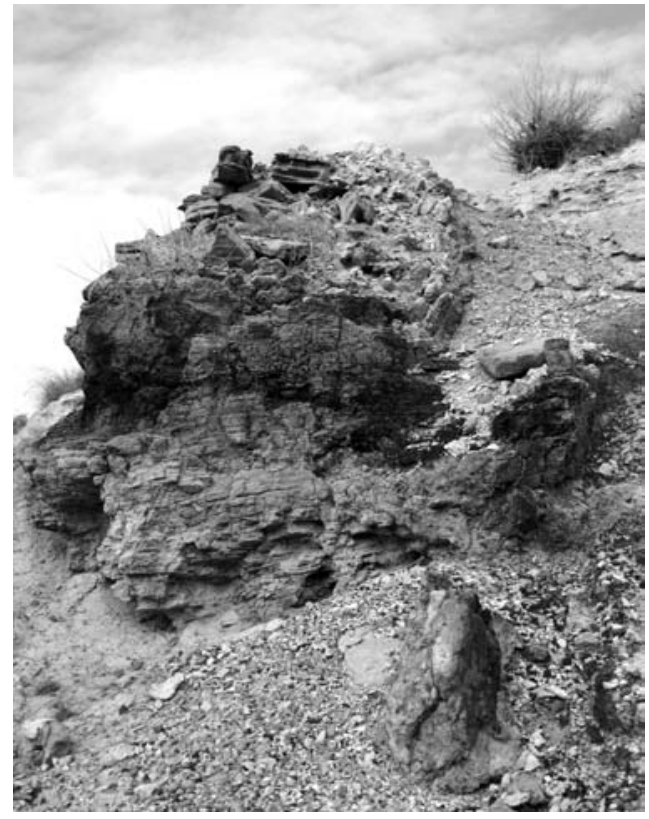

Fotografía 9.-Caldera del horno de Bodegas, 2014.

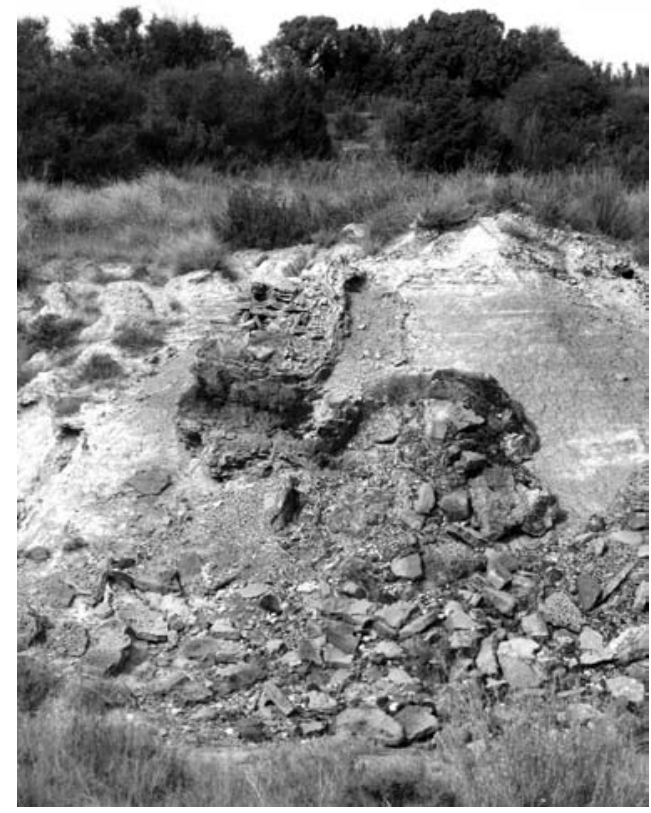

FOTOGRAFía 10.-Caldera y hoya del horno de Bodegas, 2014.

${ }^{26}$ Estos datos han sido extraídos de las fichas del Inventario Arqueológico de Navarra. 
colmatadas y habiendo perdido su falsa bóveda. Bóvedas que parece que fueron levantadas con menos de dos metros y medio de altura con adobe endurecido por la acción de un fuego interno previo a su uso final. Se situaban semienterrados en desniveles o cortados de los barrancos y conectados con una hoyada a menor altura y de dimensiones más pequeñas. Éstas fueron erigidas con el mismo material de barro. Frente a ellas en muchos casos se han encontrados restos de material pétreo. En el caso del Vedado de Eguaras está documentado por Sesma y García (1994: 182) que la base era un zócalo de piedra para probablemente facilitar el depósito de la brea cocida.

Al estar semienterradas las cavidades se facilitaba el poder calorífico de la quema y la cocción del subproducto. En todos los hornos se han hallado restos de tizones. Sin embargo, ninguno conserva la estructura de la fiera final. La antigua existencia de esta salida del alquitrán puede estar avalada por los restos de bloques roqueños hallados en las partes bajas exteriores de las pegueras. Hay que añadir, que el territorio bardenero sufre una dura y constante erosión debido a la climatología y la frágil composición de sus suelos. Tal desgaste unido a su situación quebrada en la orografía, cerca de cauces torrenciales ocasionales pero violentos, ha podido limar e ir desplomando estas estructuras durante el paso de los años.

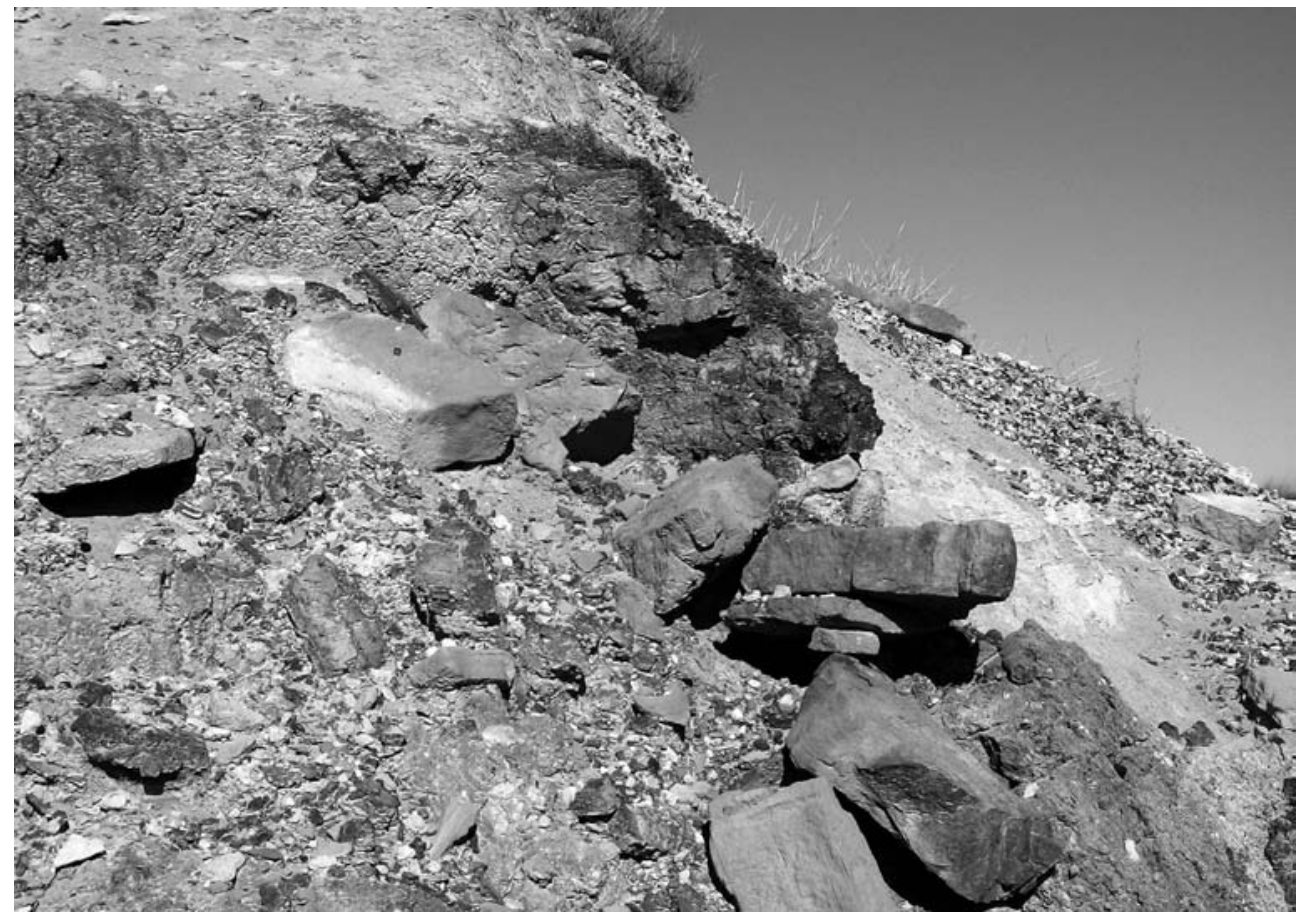

Fotografía 11._-Bloques de sillarejo de posible fiera en el horno de Bodegas, 2014.

Nos atendemos a los datos que nos aporta el Inventario Arqueológico de Navarra es evidente que la situación sobre la cartografía de estas pegueras se halla vinculada a asentamientos de yacimientos unidos a diferentes clasificaciones culturales. Se podría 
pensar que esta alineación pudiera ser cronológica y de factura, aunque es más razonable pensar que se deba simplemente a la valía estrategia de tales secciones del territorio y a condicionantes geográficos. Es decir, a su cercanía a cauces fluviales y a su ubicación en promontorios destacados del terreno. Ya se comentó que dentro de los hornos no se han hallado ni herramientas ni materiales que permitan su datación de forma certera en un periodo histórico concreto. Si nos ceñimos sólo a la documentación histórica de archivo tal datación está certificada simplemente desde el siglo XV d.C. En cualquier caso, en el siguiente cuadro comparativo se pueden visualizar los rasgos cartográficos, físicos, culturales y estructurales de estas pegueras localizadas.

\section{Hornos de PeZ localizados en las Bardenas Reales}

(Fuente: Elaboración propia ${ }^{27}$ )

\begin{tabular}{|c|c|c|c|c|c|c|}
\hline Paraje & Datos del horno & $\begin{array}{c}\text { UTM } \\
\text { (ETRS-89) }\end{array}$ & Altimetria & $\begin{array}{l}\text { Yacimiento } \\
\text { asociado }\end{array}$ & Observaciones & $\begin{array}{c}\text { Signatura } \\
\text { Inventario } \\
\text { Arqueológico } \\
\text { de Navarra }\end{array}$ \\
\hline $\begin{array}{l}\text { Barranco } \\
\text { de las } \\
\text { Bodegas }\end{array}$ & $\begin{array}{l}\text { Horno ovalado con } \\
\text { restos de material pétreo } \\
\text { y de tizones. Se } \\
\text { conserva la estructura } \\
\text { de cámara y la hoya } \\
\text { aunque ambas } \\
\text { colmatadas y sin la falsa } \\
\text { bóveda la primera. Las } \\
\text { piedras de sillarejo } \\
\text { dispersas a los pies del } \\
\text { pozo inferior podrian } \\
\text { ser restos de la fiera. }\end{array}$ & $\begin{array}{l}\mathrm{X}= \\
628749 \\
\mathrm{Y}=4681144\end{array}$ & $342 / 343$ & & $\begin{array}{l}\text { Horno no } \\
\text { incluido en el } \\
\text { Inventario } \\
\text { Arqueológico de } \\
\text { Navarra. }\end{array}$ & $\begin{array}{l}\text { No } \\
\text { inventariado. }\end{array}$ \\
\hline $\begin{array}{l}\text { Tollo del } \\
\text { Campo de } \\
\text { Pancho- } \\
\text { Cabaña de } \\
\text { Cancio- } \\
\text { Cabaña de } \\
\text { José el } \\
\text { Hornero- } \\
\text { Cabaña de } \\
\text { Zoco }\end{array}$ & $\begin{array}{l}\text { Horno ovalado con } \\
\text { restos de material pétreo } \\
\text { y de tizones. Se } \\
\text { conserva la estructura } \\
\text { de cámara }(2,20 \text { de } \\
\text { diámetro) y hoya }(1,20 \\
\text { de diámetro) aunque } \\
\text { ambas colmatadas y sin } \\
\text { la falsa bóveda la } \\
\text { primera. Las piedras } \\
\text { dispersas a los pies del } \\
\text { pozo inferior podrian } \\
\text { ser restos de la fiera. Las } \\
\text { paredes de la cámara } \\
\text { son de } 20 \mathrm{Cm} \text {. de grosor }\end{array}$ & $\begin{array}{l}X= \\
630005 \\
Y=4683577\end{array}$ & $370 / 373$ & $\begin{array}{l}\text { Barranco del } \\
\text { Horno de la } \\
\text { Pez II }\end{array}$ & $\begin{array}{l}\text { Yacimiento de } \\
\text { categoria } 2 \text { con } \\
\text { clasificación } \\
\text { cultural propia } \\
\text { de época } \\
\text { moderna. }\end{array}$ & $\begin{array}{l}\text { Cod. } \\
09315020009\end{array}$ \\
\hline $\begin{array}{l}\text { Corralicos - } \\
\text { Paso del } \\
\text { Cebedeo }\end{array}$ & $\begin{array}{l}\text { Horno ovalado con } \\
\text { restos de fogaril y } \\
\text { cerámicas más modernas } \\
\text { en el alto del monticulo. } \\
\text { También se vieron } \\
\text { elementos de material } \\
\text { pétreo y de tizones. Se } \\
\text { conserva la estructura } \\
\text { de cámara ( } 2 \mathrm{~m} \text {. } \\
\text { diámetro) y la hoya } \\
\text { (1,45 m. diámetro, 1,65 } \\
\text { m. altura y } 0,50 \\
\text { diámetro su boca } \\
\text { superior) aunque ambas } \\
\text { colmatadas y sin la falsa } \\
\text { bóveda la primera. Las } \\
\text { piedras dispersas a los } \\
\text { pies del pozo inferior } \\
\text { podrian ser restos de la } \\
\text { fiera. }\end{array}$ & $\begin{array}{l}X= \\
62510 \\
Y=4682469\end{array}$ & $342 \mathrm{~m}$. & $\begin{array}{l}\text { Paso del } \\
\text { Cebedeo }\end{array}$ & $\begin{array}{l}\text { Yacimiento de } \\
\text { categoria } 2 \text { con } \\
\text { clasificación } \\
\text { cultural propia } \\
\text { de época } \\
\text { moderna. En él } \\
\text { se hallaron } \\
\text { arcillas } \\
\text { (Barandiarán et } \\
\text { al. } 1988 \text { y } \\
\text { Sesma 1988). }\end{array}$ & $\begin{array}{l}\text { Cod. } \\
09315020026\end{array}$ \\
\hline
\end{tabular}

${ }^{27}$ Para su configuración se han seguido los datos obtenidos de la observación del trabajo de campo realizado y de las fichas del Inventario Arqueológico de Navarra. 


\begin{tabular}{|c|c|c|c|c|c|c|}
\hline Paraje & Datos del horno & $\begin{array}{c}\text { UTM } \\
\text { (ETRS-89) }\end{array}$ & Altimetria & $\begin{array}{c}\text { Yacimiento } \\
\text { asociado }\end{array}$ & Observaciones & $\begin{array}{c}\text { Signatura } \\
\text { Inventario } \\
\text { Arqueológico } \\
\text { de Navarra }\end{array}$ \\
\hline $\begin{array}{l}\text { Cueva de } \\
\text { Col - } \\
\text { Campo del } \\
\text { Olivero }\end{array}$ & $\begin{array}{l}\text { Se trata de un horno } \\
\text { ovalado con restos de } \\
\text { una arquitectura de } \\
\text { muro de piedra de } \\
\text { sillarejo con argamasa } \\
\text { de barro que } \\
\text { posiblemente fue una } \\
\text { cabaña. Se ven } \\
\text { fragmentos de tizones. } \\
\text { Se conserva la estructura } \\
\text { de cámara y la hoya } \\
\text { aunque ambas } \\
\text { colmatadas y sin la falsa } \\
\text { bóveda la primera. Las } \\
\text { piedras dispersas } \\
\text { alrededor del pozo } \\
\text { podrian ser restos de la } \\
\text { falsa cúpula. }\end{array}$ & \begin{tabular}{|l}
$X=$ \\
625696 \\
$Y=4681521$
\end{tabular} & $\begin{array}{l}335 / 337 \\
\mathrm{~m} .\end{array}$ & Cueva de Col & $\begin{array}{l}\text { Yacimiento de } \\
\text { categoria } 2 \text { con } \\
\text { clasificación } \\
\text { cultural propia } \\
\text { de épocas } \\
\text { medieval y } \\
\text { moderna. En él } \\
\text { se halló } \\
\text { cerámica de la } \\
\text { Edad Media y } \\
\text { un maravedi } \\
\text { probablemente } \\
\text { de Edad } \\
\text { Moderna (Sesma } \\
\text { 1988). }\end{array}$ & $\begin{array}{l}\text { Cod. } \\
09315020071\end{array}$ \\
\hline La Blanca & $\begin{array}{l}\text { Horno situado en un } \\
\text { cerro en la ladera } \\
\text { sudeste que está } \\
\text { bastante erosionada. Sus } \\
\text { muros presentan dos } \\
\text { hiladas y hay esparcidos } \\
\text { fragmentos pétreos que } \\
\text { podrian ser } \\
\text { estructurales. }\end{array}$ & \begin{tabular}{|l|}
$X=$ \\
629203 \\
$Y=4669623$
\end{tabular} & $314 / 321 \mathrm{~m}$ & Zapata I & $\begin{array}{l}\text { Yacimiento de } \\
\text { categoria } 2 \text { con } \\
\text { clasificación } \\
\text { cultural propia } \\
\text { de épocas del } \\
\text { hierro, y } \\
\text { romana. Se trata } \\
\text { de villa-caserio. }\end{array}$ & $\begin{array}{l}\text { Cod. } \\
09315020058\end{array}$ \\
\hline La Bandera & $\begin{array}{l}\text { Horno de planta circular } \\
\text { excavado en el suelo de } \\
\text { marga con revestimiento } \\
\text { de barro e hileras de } \\
\text { sillarejo. }\end{array}$ & \begin{tabular}{|l|}
$X=$ \\
627976 \\
$Y=4659993$
\end{tabular} & $404 \mathrm{~m}$. & $\begin{array}{l}\text { El Moscardón } \\
\text { II }\end{array}$ & $\begin{array}{l}\text { Yacimiento de } \\
\text { categoria } 3 \text { con } \\
\text { clasificación } \\
\text { cultural propia } \\
\text { de época } \\
\text { moderna y } \\
\text { contemporánea }\end{array}$ & $\begin{array}{l}\text { Cod. } \\
09315020218\end{array}$ \\
\hline $\begin{array}{l}\text { La Cuesta } \\
\text { de Hierro - } \\
\text { Cañada }\end{array}$ & $\begin{array}{l}\text { Horno circular excavado } \\
\text { en una ladera propia de } \\
\text { un barranco encajado. } \\
\text { Sus paredes son de } \\
\text { barro cocido y están } \\
\text { reforzadas en su parte } \\
\text { superior con sillarejos } \\
\text { de caliza. } \\
\end{array}$ & $\begin{array}{l}X= \\
622953 \\
Y=4660281\end{array}$ & $338 \mathrm{~m}$. & $\begin{array}{l}\text { La Cuesta de } \\
\text { Hierro } 1\end{array}$ & $\begin{array}{l}\text { Yacimiento de } \\
\text { categoria } 3 \text { con } \\
\text { clasificación } \\
\text { cultural propia } \\
\text { de época } \\
\text { moderna y } \\
\text { contemporánea }\end{array}$ & $\begin{array}{l}\text { Cod. } \\
09315020248\end{array}$ \\
\hline $\begin{array}{l}\text { Portillo de } \\
\text { Santa } \\
\text { Margarita }\end{array}$ & $\begin{array}{l}\text { Se conservan restos de } \\
\text { una hoyada que podria } \\
\text { tratarse de la propia } \\
\text { Hoya o de la cámara del } \\
\text { horno. }\end{array}$ & $\begin{array}{l}X= \\
631414 \\
Y=466288\end{array}$ & $\begin{array}{l}385 / 396 \\
\text { m. }\end{array}$ & $\begin{array}{l}\text { Barranco de } \\
\text { Tudela } 1\end{array}$ & \begin{tabular}{|l} 
Yacimiento de \\
categoria 2 con \\
clasificación \\
cultural propia \\
de épocas \\
neolitica, \\
eneolitica, \\
moderna y \\
contemporánea. \\
Se trata de un \\
lugar de \\
habitación al \\
aire libre (Sesma \\
y Garcia 1994).
\end{tabular} & \begin{tabular}{|l|} 
Cod. \\
09315020089
\end{tabular} \\
\hline $\begin{array}{l}\text { Portillo de } \\
\text { Santa } \\
\text { Margarita }\end{array}$ & $\begin{array}{l}\text { Horno localizado en el } \\
\text { cortado de un barranco. } \\
\text { Posee una cámara de } \\
\text { gran tamaño con } 4 \mathrm{~m} \text { de } \\
\text { diámetro y dos hoyadas } \\
\text { de } 1,5 \text { m. de diámetro. } \\
\text { Se ha conformado en } \\
\text { una colina artificial. Se } \\
\text { conserva la falsa cúpula } \\
\text { original }\end{array}$ & \begin{tabular}{|l|}
$X=$ \\
632548 \\
$Y=4662473$
\end{tabular} & $\begin{array}{l}400 / 402 \\
\text { m. }\end{array}$ & Malrapate VIII & $\begin{array}{l}\text { Yacimiento de } \\
\text { categoria } 2 \text { con } \\
\text { clasificación } \\
\text { cultural propia } \\
\text { de época } \\
\text { moderna y } \\
\text { contemporánea }\end{array}$ & $\begin{array}{l}\text { Cod. } \\
09315020224\end{array}$ \\
\hline
\end{tabular}




\begin{tabular}{|c|c|c|c|c|c|c|}
\hline Paraje & Datos del horno & $\begin{array}{c}\text { UTM } \\
\text { (ETRS-89) }\end{array}$ & Altimetria & $\begin{array}{l}\text { Yacimiento } \\
\text { asociado }\end{array}$ & Observaciones & $\begin{array}{c}\text { Signatura } \\
\text { Inventario } \\
\text { Arqueológico } \\
\text { de Navarra }\end{array}$ \\
\hline $\begin{array}{l}\text { Portillo de } \\
\text { Santa } \\
\text { Margarita }\end{array}$ & $\begin{array}{l}\text { Se trata de un horno } \\
\text { situado en niveles } \\
\text { calcáreos tabulares a } \\
\text { mitad de pendiente. Su } \\
\text { planta es circular con } \\
\text { paredes de adobe hasta } \\
\text { media altura y sobre las } \\
\text { cuales se reforzó con } \\
\text { sillarejo calizo. }\end{array}$ & $\begin{array}{l}\mathrm{X}- \\
632546 \\
\mathrm{Y}=4662622\end{array}$ & $\begin{array}{l}416 / 417 \\
\text { m. }\end{array}$ & Malrapate IX & \begin{tabular}{|l} 
Yacimiento de \\
categoria 3 con \\
clasificación \\
cultural propia \\
de época \\
romana y \\
contemporánea.
\end{tabular} & \begin{tabular}{|l|} 
Cod. \\
09315020263
\end{tabular} \\
\hline $\begin{array}{l}\text { Portillo de } \\
\text { Santa } \\
\text { Margarita }\end{array}$ & $\begin{array}{l}\text { Horno localizado en la } \\
\text { ladera de un barranco } \\
\text { con un diámetro de } 3 \\
\text { m. en la caldera sobre la } \\
\text { que se levantan paredes } \\
\text { de barro cocido con } \\
\text { hiladas de sillarejos en } \\
\text { su extremo superior. }\end{array}$ & $\begin{array}{l}X= \\
632581 \\
Y=4662580\end{array}$ & $414 \mathrm{~m}$. & Malraparte X & \begin{tabular}{|l|} 
Yacimiento de \\
categoria 3 con \\
clasificación \\
cultural propia \\
de época \\
moderna y \\
contemporánea.
\end{tabular} & \begin{tabular}{|l|} 
Cod. \\
09315020264
\end{tabular} \\
\hline $\begin{array}{l}\text { Barranco } \\
\text { de Tudela }\end{array}$ & $\begin{array}{l}\text { Horno ovoide ubicado } \\
\text { en un cortado con } \\
\text { pequeño desnivel del } \\
\text { que sólo es visible la } \\
\text { planta al estar la cámara } \\
\text { colmatada. Sus paredes } \\
\text { eran de adobe } \\
\text { reforzadas con sillarejos } \\
\text { de caliza. En los } \\
\text { alrededores habia restos } \\
\text { de escorias. }\end{array}$ & $\begin{array}{l}X= \\
624435 \\
Y=4660292\end{array}$ & $\begin{array}{l}380 / 393 \\
\text { m. }\end{array}$ & La Futura II & \begin{tabular}{|l|} 
Yacimiento de \\
categoria 2 con \\
clasificación \\
cultural propia \\
del Calcolitico- \\
Eneolitico, \\
Moderna y \\
Contemporánea. \\
Se trata de un \\
lugar de \\
habitación al \\
aire libre \\
\end{tabular} & $\begin{array}{l}\text { Cod. } \\
09315020249\end{array}$ \\
\hline $\begin{array}{l}\text { Los } \\
\text { Blancos y } \\
\text { Sarda del } \\
\text { Moral }^{\text {so }}\end{array}$ & $\begin{array}{l}\text { Horno ovalado } \\
\text { sustentado en la ladera } \\
\text { meridional de un } \\
\text { monticulo erosionado. } \\
\text { Sobre una planta con } \\
\text { zócalo de piedra se } \\
\text { observan restos de sus } \\
\text { paredes de adobe de } \\
0,20 \text { de grosor. Posee } \\
\text { una altura de } 2,25 \mathrm{~m} \text {. } \\
\text { bajo la cual hay un } \\
\text { estrato d } 0,44 \mathrm{~m} \text {. de } \\
\text { tierra compacta con } \\
\text { carbón y pequeñas } \\
\text { piedras. Su diámetro } \\
\text { máximo es de } 3,30 \mathrm{~m} \text {. }\end{array}$ & $\begin{array}{l}X= \\
62090 \\
Y=4678219\end{array}$ & $325 / 330 \mathrm{~m}$. & $\begin{array}{l}\text { Vedado de } \\
\text { Eguaras III } \\
\text { Junto a la } \\
\text { muga de } \\
\text { Bardenas } \\
\text { Reales) }\end{array}$ & \begin{tabular}{|l} 
Yacimiento de \\
categoría 3 con \\
clasificación \\
cultural romana. \\
Se localizó en él \\
una villa-caserió \\
(Sesma y Garcia \\
1991 y 1994).
\end{tabular} & \begin{tabular}{|l|} 
Cod. \\
09312490037
\end{tabular} \\
\hline
\end{tabular}

FOTOGRAFÍA 12.-Restos de cabaña en la peguera de Col, 2014.

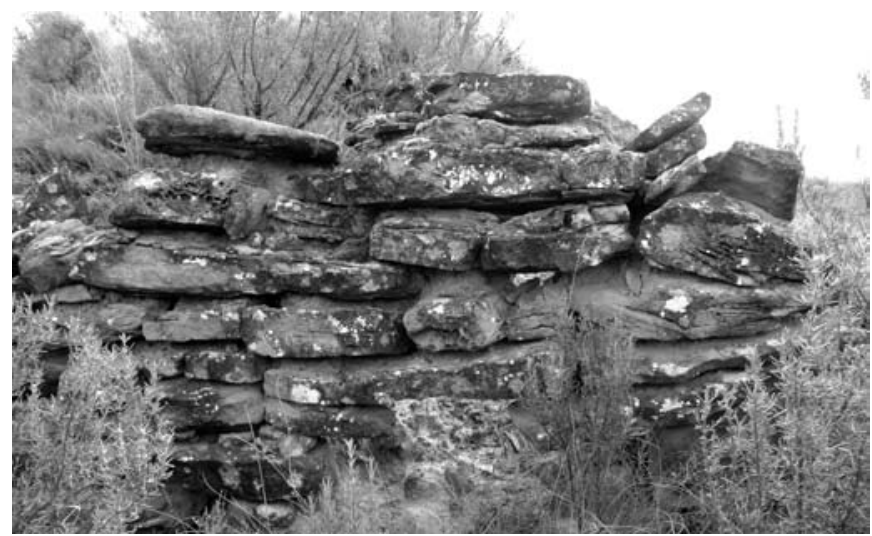

${ }^{28}$ A pesar de que las 1.200 ha. del Vedado de Eguaras o de Peñaflor (Valtierra) no son una parte componente del Parque Natural de las Bardenas Reales de Navarra, este espacio — reserva natural - por su historia y paisaje físico y humano de forma clara, geográfica y antropológicamente hablando, queda integrado dentro de un todo común. 
Fotografía 13.- - Hoya del horno de Cancio, 2014.

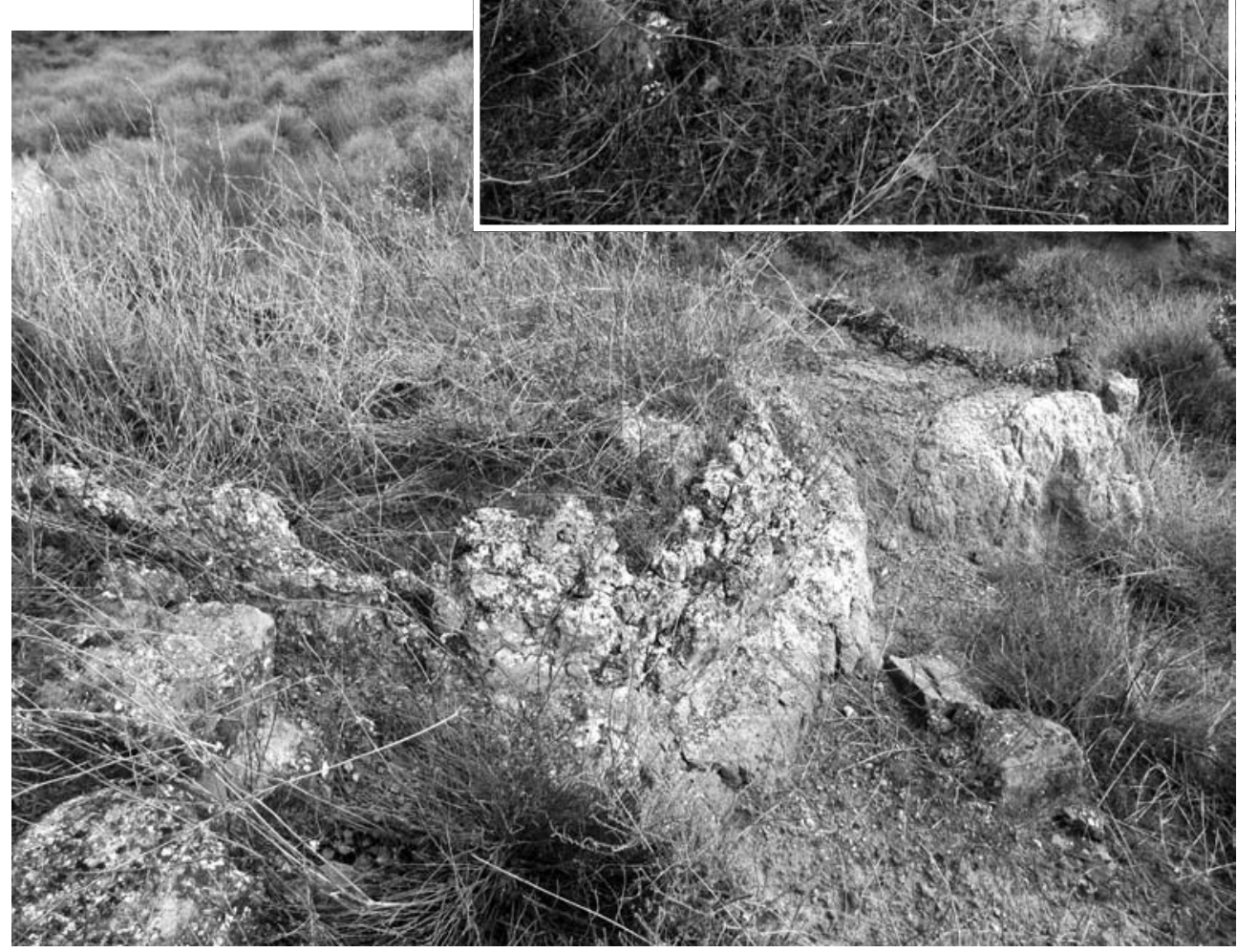

Fotografía 14.-Caldera y hoyada del horno de Cancio, 2014. 


\section{VALORACIÓN FINAL}

Del trabajo de campo iniciado en 2007 y del análisis de la diferente documentación, lo más reseñable no es tanto la descripción de sus características estructurales sino el poder dar constancia de su propia existencia. Se ha mencionado que se trata de un oficio tradicional más que extinguido en esta zona del Mediodía navarro. De hecho no se halla presente en la memoria de los habitantes locales y los rastros que ha dejado en el paisaje son sus desmochadas infraestructuras de hornear, pequeñas señales en la toponimia menor y algunos documentos históricos de archivo.

Sin embargo, ha quedado constatado cómo la producción de pez tuvo un papel importante no sólo dentro del Reino de Navarra sino en toda la Monarquía hispánica. Una trascendencia que abarcaba incluso en su influencia a zonas lejanas, llegando hasta las Indias ${ }^{29}$. Por el contrario, hoy en día el uso de esta brea manufacturada se ha reducido a su labor en la ejecución de pellejos dentro de la botería local y al marcado de reses de ganado trashumante.

FOTOGRAFÍA 15 - -

Resto de tizón

o escoria

del horno

del Cebedeo,

2013.

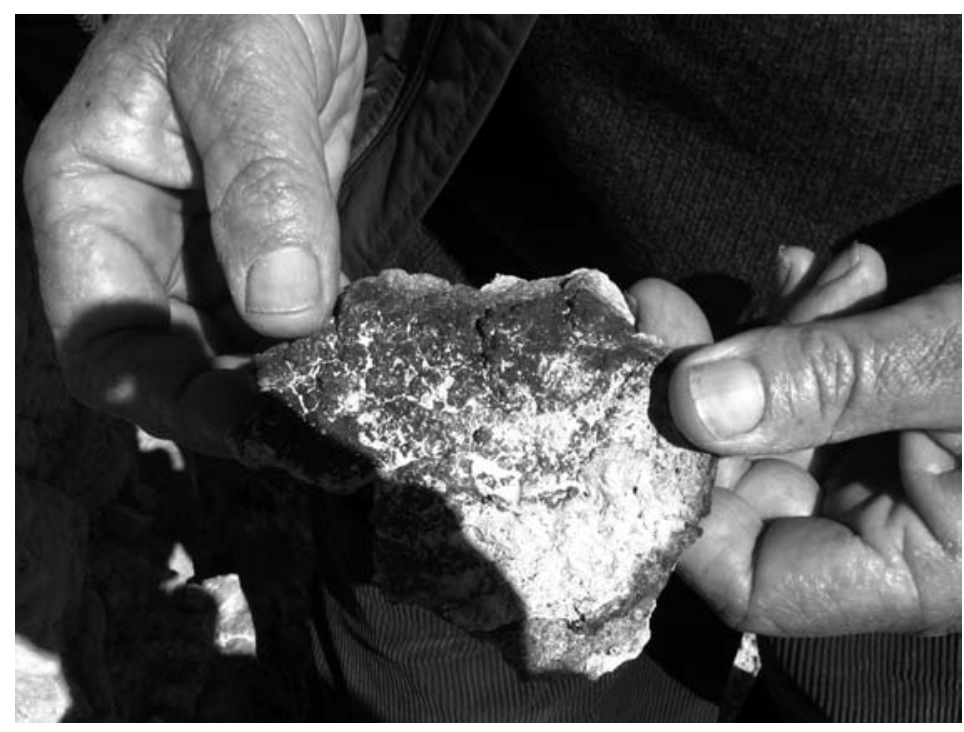

${ }^{29}$ En 1575, Bernal Díaz del Castillo daba por concluida su Historia verdadera de la conquista de la Nueva España. En tal crónica, de primera mano, el autor nos relata en una ocasión lo importante que eran la pez y el oficio de la brea para la continuidad de la expediciones al Nuevo Mundo. En Indias carecían casi de árboles propicios y de operarios diestros para la obtención de estos alquitranes esenciales en el calafateado de sus botes y bergantines: "Y luego despachó Cortes a Villa Rica por mucho yerro y clabazón de los navíos que dimos al través y por anclas y velas y xarçias y cables y estopa y por todo aparejo para hazer navíos. [...] y hasta las calderas para hazer brea y todo de quantos de antes avían sacado de los navíos truxo con más de mil indios, que todos los pueblos de aquella provinçias, enemigos de mexicanos, luego se los davan para traer las cargas. Pues como no teníamos pez para brear, ni aun los indios lo sabían hazer, mandó Cortés a quatro hombres de la mar que sabían de aquel ofiçio que en unos pinares çerca de Guaxalçingo, que los ay buenos, fuesen hazer la pes" (Díaz del Castillo 2005: 390-391). 
Hay que señalar que en el actual estado de abandono en que se encuentran la totalidad de estas pegueras, se hace más que necesaria la documentación de todos aquellos ejemplos archivísticos o arqueológicos que puedan ser localizados. En tal análisis hay que poner en relieve tanto sus propias características como la singularidad de su ubicación. Sólo así cobrarán un mayor valor patrimonial erigiéndose en muestras originales de las manifestaciones de una labor artesanal antaño relevante y que podemos señalar ya como desaparecida en esta comarca bardenera.

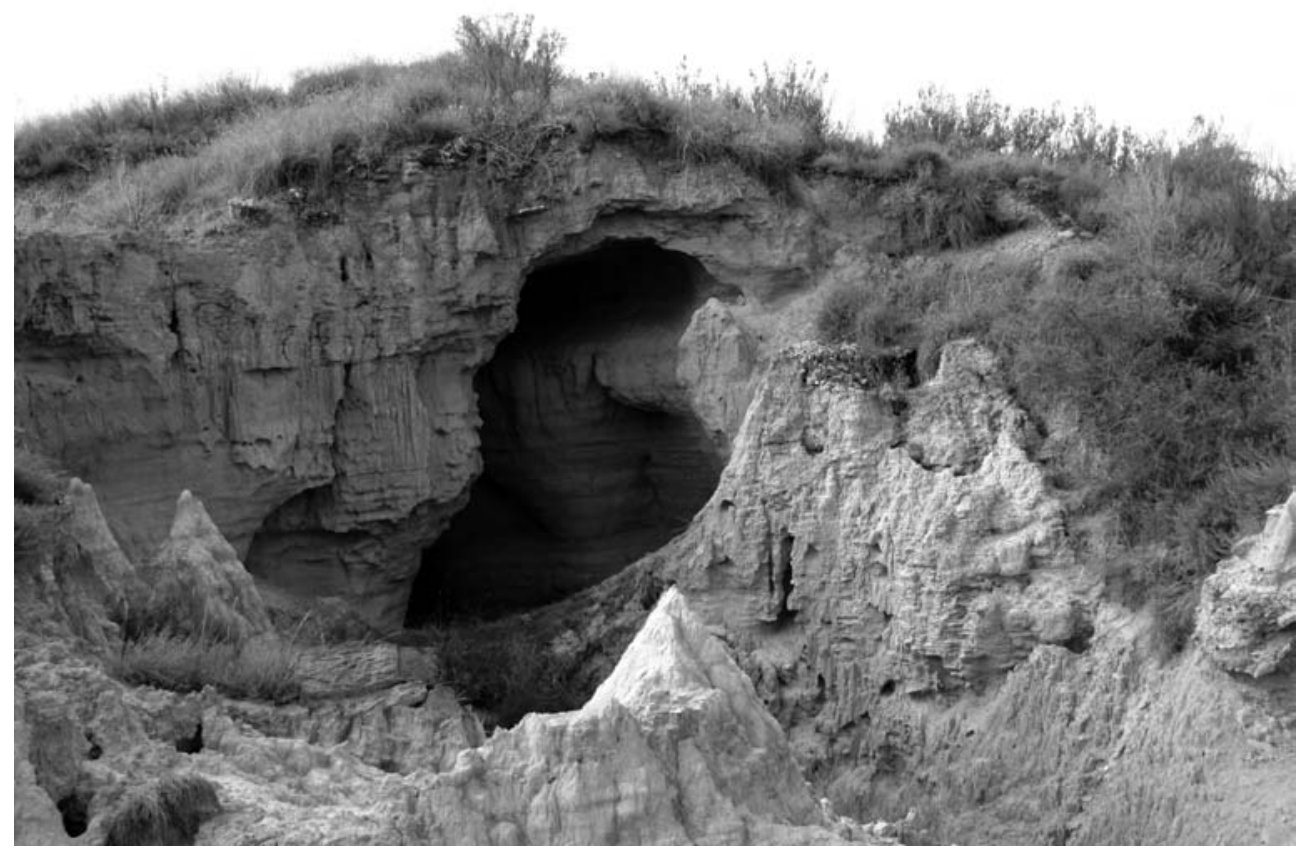

Fotografía 16.-Paraje de la Cueva de Col - Campo del Olivero, 2014.

Si atendemos a la morfología de las pegueras estudiadas es obvio que coincide a grandes rasgos con la del resto de centros empecinados de la Península y Canarias. Todos ellos presentan un horno de forma más o menos ovalada con un diámetro que varía según la capacidad de combustión de madera y producción de brea de cada ingenio. Su posición semienterrada y ubicación en desnivel venían determinadas por las necesidades de usar la gravedad con objeto de ir haciendo filtrar y circular el alquitrán desde la cámara a la segunda hoya. Además, ese soterramiento permitía una mayor capacidad de elevación de la temperatura lograda en la combustión y, por ende, de producción alquitranada. Con esta misma finalidad, y para una extracción más fácil del viscoso líquido pardo-amarillento, se posicionaba probablemente una fiera exterior, que en ninguno de los casos localizados ha podido ser observada y registrada por haber desaparecido presuntamente.

Podemos concluir por lo tanto que en cuanto a la importancia de su papel preindustrial y en atención a la estructura de sus sistemas, las semejanzas son más 
que respetables con el resto de ejemplos conocidos en otras comarcas. No obstante, cuando Pedro Orduna de Miguel, tras divisar algunos de estos hornos en su pastorear, me sugirió documentar su presencia, me pareció una interesante opción. Con ella se podría ampliar el mapa etnológico del trabajo artesanal en Navarra, si bien es cierto que durante la realización del trabajo de campo en las Bardenas Reales se me comunicó la posible existencia de más pozos aún no registrados. Estos elementos bien podrían haberse destinado a la elaboración de pez, cal o carbón. Tales noticias alimentan y sustentan la idea antropológica del gran despliegue humano y de aprovechamiento de los, en apariencia, escasos recursos naturales que este nicho ecológico del Sur navarro ha suscitado en sus comunidades limítrofes y congozantes.

Se ha conformado así un desarrollo sociocultural que no ha impedido que este paraje llegue a nuestros días como un ejemplo de equilibrio histórico en la explotación humana del espacio. Esta labor antropológica en manos de sus 'entidades tradicionales' ha permitido convertir dicha región no sólo en un Parque y Reserva de la Biosfera sino también en un constructo social independiente. Se trata de un sistema etnográfico y vivo que actúa con sus propias normas de funcionamiento. Esta realidad nos exige el conservar y analizar sus manifestaciones etnológicas, materiales e inmateriales, que en gran medida se nos presentan como perecederas.

\section{BIBLIOGRAFÍA CITADA}

Barandiarán Maestu, I. et al. 1988. "Actividad arqueológica en Navarra 1986-87». Trabajos de arqueología Navarra 7: 319-364.

Díaz del Castillo, B. 2005. Historia verdadera de la conquista de la Nueva España (Manuscrito Guatemala). Edición crítica de José Antonio Barbón Rodríguez. México D.F.: El Colegio de México.

Hernández Martín, F. 2007. "Hornos de brea y peguerías: emplazamientos industriales del siglo XVI en la isla de Tenerife". El Pajar: Cuaderno de Etnografía Canaria 23: 37-45.

Hernández Muñoz, L. 2006. El antiguo oficio resinero. Hojas divulgativas no 2116 HD. Madrid: Ministerio de Agricultura, Pesca y Alimentación.

Historia de Covaleda. 2013. "Los Hornos de Pez" http://historiadecovaleda.wordpress.com/ 2013/04/09/los-hornos-de-pez/ (Consultada 19-2- 2014).

Iribarren Rodríguez, J. Ma . 1997. Vocabulario navarro. Pamplona: Diario de Noticias. Jimeno Jurío, J. Ma. 1993. Toponimia y cartografía de Navarra. Nafarroako toponimia eta mapagintza, 15, Bardenas Reales. Pamplona: Gobierno de Navarra.

Lobo, M.; Santana, G. y Toledo, L. 1996. "Explotación y exportación de la brea en La Palma (1600-1650)». XII Coloquio de Historia Canario-Americana II: 77-97.

Martínez, R. 2010. "Las pegueras de Tierra de Pinares, Segovia”, en Sainz, J. L. y Jové, F. (coords.), La arquitectura construida en tierra: tradición e innovación. Congresos de arquitectura de tierra en Cuenca de Campos 2004/09: 197-206. Valladolid: Cátedra Juan de Villanueva. Universidad de Valladolid.

Orduna Portús, P. (coord.). 2006. Estudio etnológico sobre la artesanía y su significación cultural en Navarra. Ataun: Fundación José Miguel de Barandiarán. 
Ostolaza Elizondo, M I. 1993. "El Patrimonial del rey como defensor de los intereses reales en la Corona de Navarra". Príncipe de Viana. Anejo dedicado a: Conferencias y comunicaciones sobre Historia Moderna y Contemporánea 15: 253-264.

Real Academia Española. 2001. Diccionario de la lengua española. http://www.rae.es/ recursos/diccionarios/drae.

Santana Pérez, G. 2007. "Encuentros y transformaciones en la construcción histórica de Las Antillas y las Islas Canarias siglos XV-XVII". Anuario de Estudios Atlánticos 53: 57-97.

Sesma Sesma, J. y García García Ma. L. 1991. "Prospecciones en la Bardenas Reales de Navarra: 1990". Cuadernos de Sección. Prehistoria-Arqueología 4: 97-120.

Sesma Sesma, J. y García García Ma . L. 1994. "La ocupación desde el Bronce Antiguo a la Edad Media en las Bardenas Reales de Navarra". Cuadernos de Arqueología de la Universidad de Navarra 2: 89-218.

Sesma Sesma, J. 1988. "Prospecciones en la Bardena Blanca". Trabajos de Arqueología de Navarra 7: 355-359.

Sanz, I. 1992. "Pegueras para la obtención de la pez en la provincia de Segovia". Revista de Folklore 142: 142-144.

Soler Valencia, J. M. 2009. "Peguera de Zarzuela del Pinar". http://patrimonioindustrial ensegovia.blogspot.com.es/2009/01/peguera.html. (Consultada 19-2-2014).

Viña Bitro, A. y González Rodríguez, R. 2008. "Hornos de brea en Tenerife. Identificación y catalogación". Revista de Historia Canaria 190: 111-133.

Yanguas y Miranda, J. 1840. Diccionario de Antigüedades del Reino de Navarra. Pamplona: Imprenta de Javier Goyeneche.

Fecha de recepción: 10 de marzo de 2014

Fecha de aceptación: 15 de octubre de 2014 